Bangladesh Journal of Neuroscience 2017; Vol. 33 (1): 18-23

\title{
Sociodemographic and Clinical Factors of Acute Ischemic Stroke
}

\author{
HOSSAIN MA ${ }^{1}$, HANNAN MA², BARMAN KK³ ${ }^{3}$ BISWAS PK ${ }^{4}$, JAHAN M$^{5}$, KHAN MAM $^{6}$,
}

\begin{abstract}
:
An observational study was carried out to analyze prevalence of risk factors for ischemic stroke in hospitalized patient in a university hospital. Ninety patients were chosen by using purposive sampling technique. The mean age of patients was $59.01 \pm 9.87$ years varied from 30 to 75 years and male to female ratio was 1.2:1. Highest incidence of stroke was between the 6th and 7th decade. Patients came from both rural $49(54.4 \%)$ and urban 41 (45.6) area. Most of them belonged to the lower-middle group 70 (84.8\%). Regarding education 47 (52.2\%) patients had primary level education and 8 (8.9\%) patients were illiterate. It was observed that among them current smoker were 30 (33.3\%) and ex-smoker 17 (18.9\%). It was also observed that 52 (57.8\%) patients had hypertension and 32 (35.6\%) had diabetes mellitus (DM). Ischemic heart disease was present in 14 (15.6\%) patients. By Oxford shire classification of stroke, it was observed that PAC is common 51 (56.7\%) among all forms. Majority 38 (42.2\%) of patients had hospital stay of 11-15 days. The mean hospital stay was found $13.68 \pm 6.6$ days. This study found that cigarette smoking, hypertension, diabetes mellitus and ischemic heart diseases are the major risk factors prevalent in our community while other risk factors demand further study.
\end{abstract}

Key words: stroke, risk factors, hospitalized patients, Bangladesh.

Introduction:

Stroke is usually characterized by rapid onset of focal neurological deficit due to infarction or hemorrhage lasting more than 24 hours ${ }^{1}$. The definition of stroke is clinical. Laboratory studies including brain imaging are used to support the diagnosis $^{2}$. It is a major cause of death and disability worldwide ${ }^{3}$. Recently a study was published in Prothom Alo, a leading daily newspaper of Bangladesh which states that stroke is the first cause of adult death in Bangladesh. Countries of low and middle income have the largest burden of stroke, accounting for more than $85 \%$ of stroke mortality worldwide, but few reliable data are available to identify risk factors for stroke in most of these regions ${ }^{4}$.

To reduce burden of stroke patients, modifiable risk factors should be identified and proper treatment could reduce the incidence of acute ischemic stroke (AIS). The incidence of stroke increases with age and affect many people in their golden years. It is third most common cause of death in developed countries. The age adjusted annual death rate from stroke is 116 per 100000 populations in the USA and some 200 per 100000 in $\mathrm{UK}^{3}$. Risk factors for ischemic stroke include irreversible or non modifiable factors like age, sex, heart disease and modifiable factors like

1. Dr. Md. Amir Hossain, MBBS, FCPS (Medicine), MD (Neurology), Assistant Professor of Neurology, National Institute of Neurosciences Hospital, Dhaka

2. Professor M. A. Hannan, MBBS, FCPS (Medicine), MD (Neurology), FRCP (Edin.) Chairman, Department of Neurology, Bangabandhu Sheikh Mujib Medical University, Dhaka

3. Dr. Kanuj Kumar Barman, MBBS, MPH, MD (Neurology). Associate Professor, Department of Neurology, Bangabandhu Sheikh Mujib Medical University.

4. Dr. Prodip Kumar Biswas, MBBS, FCPS (Medicine), MD (Gastro). Associate Professor of Medicine, Dhaka Medical College, Dhaka.

5. Dr. Merina Jahan, FCPS (Obs \& Gynae), Lecturer, Dhaka Medical College, Dhaka.

6. Dr Muhammad Abdul Momen Khan, MBBS, MD (Neurology). Assistant Professor of Neurology, National Institute of Neurosciences Hospital, Dhaka 
hypertension, heart disease, diabetes mellitus, hyperlipidemia, smoking, excess alcohol, polycythemia and oral contraceptive ${ }^{3}$. The morbidity and mortality from cerebrovascular disease has been diminished in recent years largely due to better recognition and treatment of underlying arterial and cardiac disease including hypertension, diabetes and hyperlipidemia. There is no cure in management of stroke. But prevention is possible by early detection and reducing the modifiable risk factors. This is very much important in the concept of our country where medical facilities and resources are limited and most of the people lives below poverty level.

\section{Materials and Methods:}

This observational study was conducted in the department of Neurology of Bangabandhu Sheikh Mujib Medical University (BSMMU), Dhaka, Bangladesh during January 2013 to December 2013 and received prior approval from Ethical Review Committee of BSMMU and all participants gave informed written consent. All collected data were checked, edited and analyzed by using computer based SPSS software version 16.0. Samples were collected purposively. Data were presented by frequency distribution and percentage. Parametric data was expressed in mean \pm SD. Categorical data was evaluated by Chi square test. Significance was defined by $p$ value $<0.05$.

A total of 90 AIS patients admitted in the Neurology department of BSMMU were included in this study. Sampling technique was purposive. Patients presented with first ever AIS, confirmed by CT scan/ MRI of brain from 01 day to 02 weeks were enrolled in this study. Hemorrhagic stroke were excluded from the study.

After selection of subjects, detailed history, clinical examinations and all other informations regarding sociodemographic and clinical factors of AIS were taken in a prescribed data collection form. Relevant baseline investigations (e.g-complete blood count, urine $R / M / E$ etc.) were performed. Imaging study (CT/MRI) was done for diagnosis and categorization of stroke. AIS subtype is defined by Oxfordshire Community Stroke Project classification (OCSP) criteria. Cerebral infarctions were divided into the following clinical categories: total anterior circulation infarcts (TACl), partial anterior circulation infarcts (PACl), lacunar infarcts $(\mathrm{LACl})$, and posterior circulation infarcts ( $\mathrm{POCl})$.

Length of hospital stay (LOHS) was measured in days from day of admission.

\section{Results:}

Out of the 90 AIS patients, majority $36(40 \%)$ were belonged to age group of 61-70 years. The mean age was found 59 years with range from 30 to 75 years (Table I).

Table-I

Socio-demographic characteristics of the study patients $(n=90)$

\begin{tabular}{llcc}
\hline Characteristics & \multicolumn{3}{c}{$\begin{array}{c}\text { No. of } \\
\text { respondents }\end{array}$} \\
\hline Sex & Male & 49 & 54.4 \\
\multirow{4}{*}{ Age } & Female & 41 & 45.6 \\
& d"40 & 7 & 7.8 \\
& $41-50$ & 9 & 10.0 \\
& $51-60$ & 34 & 37.8 \\
Residence & $61-70$ & 36 & 40.0 \\
Monthly family & Urban & 4 & 4.4 \\
income (Taka) & Low income & 14 & 45.6 \\
& & 49 & 54.4 \\
& Lower middle & 70 & 15.6 \\
& Upper middle & 6 & 77.7 \\
Educational & Upper & 0 & 6.6 \\
status & Illiterate & 8 & 0 \\
& Primary & 47 & 8.9 \\
& SSC & 20 & 52.2 \\
& HSC & 10 & 22.2 \\
& Graduate \& & 5 & 11.1 \\
& above & & 5.6 \\
\hline
\end{tabular}

*The state of the world's children 2012

Low-income $=<7000$

Lower-middle income $=7000-27000$

Upper-middle $=27000-84000$

High income $=>84000$

It was observed that more than half $(54 \%)$ were male and $41(46 \%)$ were female. Male to female ratio was 1.2:1. It also showed that $49(54 \%)$ patients came from rural area and $41(46 \%)$ came from urban area (Table I). Regarding monthly family income of the patients it was observed that 14 $(15.6 \%)$ patients came from low-income group, 70 
$(77.7 \%)$ came from lower-middle income group and $6(6.6 \%)$ from upper-middle group (Table I).

It was observed that $8(8.9 \%)$ patients were illiterate, $47(52.2 \%)$ patients educated at primary level, 20 (22.2\%) educated at SSC level, 10 (11.1\%) educated at HSC level and 5(5.6\%) educated at graduate \& above in this study regarding educational status (Table I).

Regarding smoking status of the patients nonsmoker was found in $43(47.8 \%)$ of patients. But current smoker was $30(33.3 \%)$ and ex-smoker was $17(18.9 \%)$ (Table II). And 8 (8.9\%) had habit of alcohol intake.

Table-II

Distribution of the study patients by smoking status $(n=90)$

\begin{tabular}{lcc}
\hline Smoking status & $\begin{array}{c}\text { Number of } \\
\text { patients }\end{array}$ & Percentage \\
\hline Non smoker & 43 & 47.8 \\
Current smoker & 30 & 33.3 \\
Ex-smoker & 17 & 18.9 \\
\hline
\end{tabular}

Table II shows smoking status of the patients. It was observed that non-smoker was found in $43(47.8 \%)$ patients, current smoker was $30(33.3 \%)$ and former smoker $17(18.9 \%)$.

This study revealed that $32(35.6 \%)$ patients had diabetes mellitus (DM). Among the diabetic patients $20(62.5 \%)$ had diabetes for less than 5 years and $12(37.5 \%)$ for $\geq 5$ years (Table III)

Table-III

Distribution of the study patients by history of diabetes mellitus ( $n=90)$

\begin{tabular}{lcc}
\hline Diabetes Mellitus & $\begin{array}{c}\text { Number of } \\
\text { patients }\end{array}$ & Percentage \\
\hline No & 58 & 64.4 \\
Yes & 32 & 35.6 \\
Duration of DM & & \\
$<5$ years & 20 & 62.5 \\
$\geq 5$ years & 12 & 37.5 \\
\hline
\end{tabular}

Table III shows diabetes mellitus of the patients. It was observed that 32(35.6\%) patients had diabetes mellitus. Among the diabetic patients $20(62.5 \%)$ had diabetes for less than 5 years and $12(37.5 \%)$ for $\geq 5$ years.

Table-IV

Distribution of the study patients by history of hypertension $(n=90)$

\begin{tabular}{lcc}
\hline Hypertension & Number of patients & Percentage \\
\hline Yes & 52 & 57.8 \\
No & 38 & 42.2 \\
\hline
\end{tabular}

Table IV shows hypertension of the study patients. It was observed that $52(57.8 \%)$ patients had hypertension and $38(42.2 \%)$ had no hypertension.

It was observed that $52(57.8 \%)$ patients were hypertensive and $38(42.2 \%)$ had no history of hypertension (Table IV). Fourteen (15.6\%) had a history of ischemic heart disease.

Table-V

Distribution of the study patients by presentation $(n=90)$

\begin{tabular}{lcc}
\hline Presentation & $\begin{array}{c}\text { Number of } \\
\text { patients }\end{array}$ & Percentage \\
\hline Hemiparesis/Monoparesis & 71 & 78.9 \\
$\begin{array}{l}\text { Hemiparesis, cranial nerve } \\
\text { involvement }\end{array}$ & 5 & 5.6 \\
Hemiparesis, Aphasia & 10 & 11.1 \\
Hemiparesis, Visual & 4 & 4.4 \\
involvement & & \\
$\begin{array}{l}\text { Duration (days) } \\
\text { 1-3 }\end{array}$ & 14 & 15.6 \\
$4-7$ & 71 & 78.9 \\
$7-14$ & 5 & 5.6 \\
\hline
\end{tabular}

Table $\mathrm{V}$ shows presentation of the study patients. It was observed that $71(78.9 \%)$ patients had hemiparesis/monoparesis; 5(5.6\%) had hemiparesis \& cranial nerve involvement; $10(11.1 \%)$ had hemiparesis \& aphasia and $4(4.4 \%)$ had hemiparesis \& visual involvement.

Regarding presentation of illness it was found that $71(78.9 \%)$ patients had hemiparesis/monoparesis; $5(5.6 \%)$ had hemiparesis \& cranial nerve involvement; $10(11.1 \%)$ had hemiparesis \& aphasia and $4(4.4 \%)$ had hemiparesis \& visual involvement (Table V). 
Table-VI

Distribution of the study patients by Oxford shire Classification of Stroke $(n=90)$

\begin{tabular}{lcc}
\hline CT/MRI of brain & $\begin{array}{c}\text { Number of } \\
\text { patients }\end{array}$ & Percentage \\
\hline TACLAC & 415 & 4.416 .7 \\
PAC & 51 & 56.7 \\
POC & 14 & 15.6 \\
Syndrome & 6 & 6.6 \\
\hline
\end{tabular}

Table VI shows Oxfordshire Classification of Stroke. It was observed that $4(4.4 \%)$ TAC, 15(16.7\%) LAC, 51(56.7\%) PAC, 14(15.6\%) POC and $6(6.6 \%)$ syndromes.

According to Oxford shire Classification of Stroke it was observed that 4(4.4\%) TAC, 15(16.7\%) LAC, 51(56.7\%) PAC, 14(15.6\%) POC and 6(6.6\%) were syndromes (Table VI).

Table-VII

Distribution of the patients by length of hospital stay $(n=90)$

\begin{tabular}{lcc}
\hline $\begin{array}{l}\text { Length of Hospital } \\
\text { stay (days) }\end{array}$ & $\begin{array}{c}\text { Number of } \\
\text { patients }\end{array}$ & Percentage \\
\hline$\leq 5$ & 3 & 3.3 \\
$6-10$ & 23 & 25.6 \\
$11-15$ & 38 & 42.2 \\
$16-20$ & 4 & 4.4 \\
$21-25$ & 18 & 20.0 \\
$>25$ & 4 & 4.4 \\
Mean \pm SD & \multicolumn{2}{c}{$13.68 \pm 6.6$} \\
Range (min, max) & \multicolumn{2}{c}{$(4,31)$} \\
\hline
\end{tabular}

Table VII shows length of hospital stay of the patients. It was observed that majority $38(42.2 \%)$ of patients had hospital stay of 11-15 days. The mean hospital stay was found in $13.68 \pm 6.6$ days.

Majority $38(42.2 \%)$ of patients had hospital stay of $11-15$ days. The mean hospital stay was found in $13.68 \pm 6.6$ days (Table VII).

\section{Discussion:}

Stroke frequency increases exponentially with increasing age ${ }^{11}$. Main bulk of the study subject $(40 \%)$ were in seventh decade and the mean age was 59 years varied from 30 to 75 years (Table I).
Similarly Hossain et al. in Faridpur Medical College showed highest incidence of stroke was between the sixth and seventh decade ${ }^{12}$. Kundu et al. in a Bangladeshi study showed $16 \%$ were young stroke (age<40years) and most patients (54\%) were at and above 60 years of age ${ }^{13}$. Basu et al. at a study in Kolkata National Medical college obtained that median age was 60 years, mean age $60 \pm 13$ years varied from $25-88$ years, which is closely resembled with the present study ${ }^{14}$. On the other hand, Gentile et al. showed the mean age was $65.7 \pm 13.6$ years varied from 20 to 101 years $^{3}$.In another study conducted in University of South Carolina, USA, Bhatt and Rizvi found the average age of AIS patients was 67.8 years, which are higher with the current study, this may be due to increased life expectancy, and geographical influences may have significant impacts to developed AIS of their study patients ${ }^{15}$.

In this current study it was observed that AIS was predominant in male subjects, where $54 \%$ and $46 \%$ patients were male and female respectively and male to female ratio was 1.2:1. Similar observations regarding the sex incidence were also made by Basu et al. where they found $57.0 \%$ were male and $43.0 \%$ were female ${ }^{14}$. However, Gentile et al. and Bhatt and Rizvi were found $55.0 \%$ and $57.0 \%$ patients were female respectively 3,15 . More than a half $(54 \%)$ of the patients attended from rural area and $46 \%$ came from urban. These findings are almost similar of the study done by Hossain et al. ${ }^{12}$ The reason of higher percentage of AIS in rural patients may be due to lack of knowledge regarding risk factors of stroke management and due to low economical condition.

Considering socio-economic status, the lowermiddle income group (monthly income BDT 7000$27000)$ comprised the majority $(77.7 \%)$. This result correlated with the study by Hart CL et al. which concluded that poor socioeconomic circumstances were associated with greater risk of stroke, which was also found in other studies ${ }^{16-18}$. But this study disagreed with the study of Chapman et al. which showed the incidence of stroke was high among the high-income group ${ }^{19}$. 
Regarding educational status of the patients it was observed that $8.9 \%$ patients were illiterate, $52.2 \%$ patients educated at primary level, $22.2 \%$ educated at SSC level, $11.1 \%$ educated at HSC level and $5.6 \%$ educated at graduate \& above. Hossain et al showed most of the study subjects were literate $(63 \%)^{12}$. It represents the current increasing literacy rate in Bangladesh.

It was observed that non-smoker was found in $47.8 \%$ patients, current smoker was $33.3 \%$ and ex-smoker $18.9 \%$. And $8.9 \%$ had habit of alcohol intake. In Stollberger et al. study showed 9.0\% patients were current smoker and $75 \%$ were alcoholic. Hossain et al. showed $20.75 \%$ current smoker in a Bangladeshi study ${ }^{12}$.

This study findings showed that more than one third $(35.6 \%)$ of the patients had DM and among them $62.5 \%$ had DM for less than 5 years and $37.5 \%$ for e" 5 years. Basu et al. and Bhatt and Rizvi showed $26.0 \%$ and $51.4 \%$ had a known history of DM respectively ${ }^{14,15}$. Stollberger et al. in 2005 found that $30 \%$ patients had a history of DM. ${ }^{20}$ Gentile et al. obtained DM $39.0 \%$ in their study patients ${ }^{3}$. Hossain et al. showed 21\% DM in stroke patients at Faridpur Medical College ${ }^{12}$. Kundu et al. showed DM is in $99(20 \%)$ patients $^{13}$. And of these 99 patients only $57(12 \%)$ patients were known diabetic and the remaining patients were labeled as diabetic after admission.

In current study it was observed that $57.8 \%$ patients had hypertension and $42.2 \%$ patients were normotensive. Similarly, Stollberger et al. found that $66.0 \%$ patients were hypertensive ${ }^{20}$. But $15.6 \%$ had a history of ischemic heart disease. Basu et al. and Gentile et al. showed that $74.0 \%$ and $73.8 \%$ patients were known hypertensive respectively, which is higher than the current study ${ }^{3,13}$. In a study conducted at Faridpur Medical College showed $63 \%$ were hypertensive in stroke patients and $45.83 \%$ had history of ischemic heart disease. In the study of Kundu et al. hypertensive patients were $69.60 \%$ (284) out of 500 patients $^{13}$.

Regarding presentation of the study patients, it was observed that $78.9 \%$ patients had hemiparesis/ monoparesis; $5.6 \%$ had hemiparesis \& cranial nerve involvement; $11.1 \%$ had hemiparesis \& aphasia and $4.4 \%$ had hemiparesis \& visual involvement.

Table VI shows distribution of the study patients according to Oxford shire Classification of Stroke. It was observed that $4.4 \%$ TAC, $16.7 \%$ LAC, $56.7 \%$ PAC, $15.6 \%$ POC and $6.6 \%$ syndromes.

In this present study it was observed that majority $(42.2 \%)$ of patients had hospital stay of $11-15$ days and the mean duration of hospital stay was $13.68 \pm 6.6$ days varied from $4-31$ days. Similarly, Stollberger et al. showed duration of hospitalization was 13 days varied from $9-20$ days $^{20}$. Gentile et al. and Bhatt and Rizvi (2010) observed the mean length of hospital stay were $7.40 \pm 8.15$ days and $6.12 \pm 4.2$ days respectively, which are lesser with the current study ${ }^{3}, 15$.

\section{Conclusion:}

Stroke is one of the leading causes of mortality and morbidity and it is a socioeconomic challenge. And it is very true for a developing country like Bangladesh, where health care system including the stroke rehabilitation system is not within the reach of the general people. Stroke affects not only the patients but also their family. A stroke patient is a burden for the family, society as well as for the country. The objective of this hospital-based observational study was to identify the important risk factors for ischemic stroke prevalent in our society among the urban and rural population. This study may have not reflected the exact situation but gives an utmost picture of the disease. There are many risk factors for ischemic stroke, some are modifiable and some are not. In this study a number of modifiable risk factors were identified, of these diabetes and hypertension are two important factors. Others are smoking and ischemic heart disease. Prevention is better than cure. And it is very much true for ischemic stroke patients. In a developing country like ours the best policy for combating stroke is primary prevention. This study reveals that the major risk factors diabetes and hypertension need maximum attention for the prevention of stroke. Quitting of smoking and alcoholism are also important. By controlling diabetes and hypertension we can significantly reduce the incidence of ischemic 
stroke. For this we need increase awareness among people regarding diabetes and hypertension and their complications.

\section{References:}

1. Fauci AS, Braunwald E, Kasper DL, Hauser SL, Longo DL, Jameson JL. Cerebrovascular disease. In: Harrison's Principles of Internal Medicine 17th Edition, McGraw Hill, New York. 2008.

2. Smith WS, Joey D, English S. Cerebrovascular disease. In: Harrison's Principles of Internal Medicine 18th Edition, McGraw Hill, New York. 2011; 3270-94.

3. Gentile NT, Seftchick MW, Huynh T, Kruus LK, Gaughan J. 'Decreased mortality by normalising Blood Glucose after Acute Ischemic Stroke'. Acad Emerg Med. 2006; 13: 174-80.

4. Williams LS, Rotich J, Fineberg N, Espay A, Bruno A, Fineberg SE, et al. Effects of admission hyperglycemia on mortality and costs in Acute Ischemic Stroke. Neurology. 2002; 59: 67-71.

5. Frederic MW. Cerebrovascular disease. In: Cardiac and Vascular Disease Conn HLJR and Horwitzo (eds). Lea and Febiger, Philladelphia. 1971; 1473-99.

6. Wolf PA, Cobb JL, Agostine D. Epidemiology of stroke; Stroke $2^{\text {nd }}$ Edition, Barnett HJM and Mohr JP (eds). Churchill Livingstone, Edinburgh. 1992; 3-27.

7. Houseley E. Definition of risk factors in stroke; Stroke Gillingam FJ and Mawdsley C (eds), Churchill Livingstone, New York. 1976; 251-60.

8. Grotta JC. Post-stroke management concerns and outcomes. Geriatrics. 1988;43:40-48.

9. Sacco RL, Wolf PA, Kannel WB, McNamara PM. Survival and recurrence following stroke: the Framingham study. Stroke. 1982;13: 290-95.

10. Silver FL, Norris JW, Lewis AJ, Hachinski VC. Early mortality following stroke: a prospective review. Stroke. 1984;15:492-96.
11. Allen CM. Predicting the outcome of acute stroke: a prognostic score. J Neurol Neurosurg Psychiatry.1984;47:475-80.

12. Hossain AM, Ahmed NU, Rahman M, Islam MR, Sadhya G, Fatema K. Analysis of sociodemographic and clinical factors associated with hospitalized stroke patients of Bangladesh. Faridpur Med. Coll. J. 2011; 1: 19-23.

13. Kundu NC, Ahmed Q, Sen M. 'Study of stroke and its risk Factors among admitted patients in a tertiary level hospital'. Bangladesh Journal of Neuroscience. 2010; 26: 86-91.

14. Basu S, Sanyal $D$, Roy K, Bhattacharya K. Is post-stroke hyperglycemia a marker of stroke severity and prognosis: A pilot study'. Neurology Asia. 2007; 12: 13-19.

15. Bhatt H, Rizvi AA. 'Average Inpatient Glucose Levels during the first 72 hours Clinical Outcomes, and length of hospital Stay in Patients with Acute Ischemic Stroke'. Int J Diabetes \& Metab. 2010; 18: 13-17.

16. Hart CL, Hole DJ, Smith GD. Influence of socioeconomic circumstance in early and later life on stroke risk among men in a Scottish cohort study. Stroke. 2000; 31(9): 2093-97.

17. Casper M, Wing S, Strogatz D. Variation in the magnitude of black- white differences in stroke mortality by community occupational structure. J Epidemiol Community Health. 1991; 45: 02-307.

18. Shaper AG. Risk factors for stroke in middle age British men. BMJ. 1991; 302: 1111-16.

19. Chapman JM. Epidemiology of vascular lesions affecting the central nervous system: The occurrence of stroke in a sample population under observation for cardiovascular disease. Am J Public Health. 1966; 55: 191-20.

20. Stollberger C, Exner I, Finsterer J, Slany J, Steger C. 'Stroke in diabetic and non-diabetic patients: Course and prognostic value of admission serum glucose'. Annals of Medicine. 2005; 37: 357-64. 